\title{
A VIAGEM COMO EXPERIÊNCIA DO ENCONTRO DE SI NA FIGURA DO VIAJANTE INDEPENDENTE
}

\author{
Camila Aparecida Leves Maneze \& Reinaldo Tadeu Boscolo Pacheco
}

\begin{abstract}
RESUMO
O artigo traz como reflexão $o$ ato de viajar como uma experiência significativa essencial à vida, por meio de uma abordagem qualitativa, descritiva e bibliográfica. Objetiva-se analisar o desenvolvimento da figura do viajante independente, objeto do estudo, sendo aquele que doa o seu tempo à viagem e decide viajar sem se prender às condições financeiras e sociais. Verifica, no processo da viagem, a construção da sua imagem, cuja experiência exercida com independência, pode promover transformação, conhecimento e autoconhecimento. Revela-se uma busca que está além do encontro com o outro, o desconhecido, sendo antes um reencontro de si mesmo. Consideram-se os aspectos subjetivos do ato de viajar ao analisar dois relatos literários de viajantes independentes.
\end{abstract}

\author{
PaLAVRAS-Chave
}

Ato de viajar; autoconhecimento; independência; viajantes

\section{TRAVELING AS AN EXPERIENCE OF FINDING ONESELF IN THE FIGURE OF THE INDEPENDENT TRAVELER}

\begin{abstract}
The article reflects on the act of traveling as a significant experience essential to life, through a qualitative, descriptive and bibliographical approach. The purpose of this study is to analyze the development of the figure of the independent traveler, the subject of the study, who donates his or her time to travel and decides to travel without becoming attached to financial and social conditions. It verifies, in the process of travel, the construction of its image, whose experience exercised independently, can promote transformation, knowledge and self-knowledge. It turns out a search which is beyond the encounter with the other, the unknown, being rather a reunion with oneself. The subjective aspects of the act of traveling are considered when analyzing two literary reports of independent travelers.
\end{abstract}

\section{KEYWORDS}

Independence; self-knowledge; travelers; traveling act 


\section{INTRODUÇÃo}

O ato de viajar faz parte do processo da formação social e da identidade cultural do ser humano, que se desloca desde o início da história humana, e revela suas buscas por sobrevivência, peregrinação, hedonismo, influências provindas "pela cultura e pelo imaginário" e pela necessidade de movimento ao anseio de descobrir o desconhecido (Maffesoli, 2001; Trigo, 1998, p. 25). Ao mesmo tempo que o ato desafia ao "desconhecido", coloca o ser humano ao encontro do próprio medo e estranhezas, ao reencontro de si (Cardoso, 2003).

$\mathrm{Na}$ Idade Média, o ato de viajar se limita ao medo mistificado e fecundado pela religiosidade Cristã. Mas no final do século XVII, há uma mudança de mentalidade e o gosto pelas viagens sai dos interesses exclusivamente econômicos para uma "busca de deleite e emoções, visando o aprimoramento pessoal" e estético (Salgueiro, 2002, p. 2). Surge o Grand Tour, no século XVIII, prática que se populariza e se incorpora à cultura europeia como complemento da formação aristocrática. No século XIX, há um aumento da frequência aristocrática nos balneários. E após a Revolução Industrial, os avanços das técnicas, dos meios de transporte e das novas alternativas de locomoção, inovações políticas, sociais e econômicas, propiciam a organização de viagens por Thomas Cook, considerada por alguns estudiosos, como Trigo (1998), como um dos princípios da configuração do interesse pelo viajar com o molde turístico.

Com o advento da globalização, as viagens deixam de ser apenas um símbolo de status e passam a se expressar como vivência essencial ao ser humano, fruto de uma pós-modernidade hiperconsumista, vítima de um processo de "descontrole" e "liquidificação" social, que busca por experiências significativas e sensíveis (Bauman, 1998; Giddens, 2003; Lipovetsky, 2004). As experiências significativas das viagens assumem uma nova roupagem a denominar o ato de viajar no mundo moderno e contemporâneo (Araújo, Congo \& Pinto, 2015). Surge desse cenário a representação da mobilidade, o viajante independente (Urry, 1996; Salazar, 2017). Diante disso, compreende-se o viajante independente como aquele que, literalmente, se permite guiar pelo "destino" como parte da experiência, rompe laços sociais sem preocupação temporal e financeira e sai da lógica do mercado turístico.

Neste aspecto, investiga-se a figura do viajante independente construída no percurso das viagens, a partir da análise bibliográfica e dos relatos literários reais das viagens de Chris McCandless (Krakauer,1998) e Antonio Lino (Lino, 2011) sobre este tipo de experiência enquanto vivência significativa. Fez-se uma abordagem qualitativa (Martins \& Theóphilo, 2007) e descritiva (Gil, 2002), cujo elemento central é o viajante independente. O objetivo é a compreensão e descrição do fenômeno, partindo-se da premissa que a viagem realizada nestes termos pode resultar na aprendizagem e conhecimento de si, o autoconhecimento.

O autoconhecimento, como dialética do mundo externo com o interior humano em contato com a natureza e com o outro (Cassirer, 1994) pode ser entendido como uma investigação de base epistemológica e filosófica, que ocorre desde a Grécia antiga, 
pelo constante interesse em compreender a origem da teoria humana, quanto como uma busca ou prática de base religiosa consequentes da meditação e da peregrinação.

$\mathrm{Na}$ análise interdisciplinar bibliográfica com os relatos, identificam-se o desenvolvimento da construção da imagem do sujeito que viaja com independência, sendo que dentre as características que a compõem, estão o espírito de liberdade, a aventura e a errância (aspecto do nomadismo). Compreende-se que o viajante independente parte pelo e para o desejo de viajar. Conforme Matos (1997), o desejo é sintoma para uma experiência profunda.

Sabe-se que há diversas experiências na vida. Porém, ao se tratar das viagens, nem todas são entendidas por experiências significativas, pois as experiências significativas são evidenciadas por serem "intensas e remeterem ao imediatismo, às condições específicas e à própria subjetividade" (Trigo, 2010, p. 30).

O conceito de experiência abarca duas visões inseridas no contexto do turismo (Panosso Netto, 2010): a econômica (usada como marketing comercial) e a filosófica (em seus aspectos subjetivos por meio do ato de viajar). O termo "experiência" é complexo e amplo no viés filosófico. Porém, sem se aprofundar no teor filosófico clássico, a experiência é refletida em seus aspectos subjetivos do ato de viajar. Concebe-se a viagem como expressão cultural, conforme De Botton (2012).

$\mathrm{O}$ ato de viajar independente rompe com a lógica da segurança dos roteiros massificados ou adquiridos com o poder de compra e vivenciam-se as oportunidades proporcionadas ao longo do percurso, em seus encontros e desencontros, nas mais variadas formas alternativas de experiências. Dentre elas, destacam-se as acomodações informais e independentes, formas e meios de transporte como caronas, bicicletas (veículos próprios) ou o próprio pé na estrada. Acontece o contato natural com o outro (residente local), sem simulações, buscando novas interpretações com relação aos patrimônios naturais, materiais e imateriais, isto é, volta-se o olhar para as viagens como experiências significativas que rompem com o interesse do mercado, o conformismo e conforto do cotidiano. $O$ artigo se justifica por tentar compreender esta forma de se fazer turismo, analisando o fenômeno social dos viajantes independentes. Percebe-se, assim, que o ato independente da viagem torna a experiência do viajar ainda mais significativa para o enriquecimento humano.

\section{CONSTRUÇÃO E TRANSFORMAÇÃO: VIAJANTE INDEPENDENTE}

$\mathrm{Na}$ história social do ato de viajar encontram-se vários tipos de viajantes que são denominados e sintetizados por Figueiredo (2010), conforme os seus anseios de viagem:

\footnotetext{
' As noções de experiência, no aspecto geral, demonstram-se abrangentes em suas aplicações etimológicas. Dentre elas, no termo em alemão Erfahrung vinda "do antigo alto alemão irfaran, que significa to travel ("ato de viajar"), to go out ("ato de sair") ou to wonder ("ato de admirar-se, deslumbrar-se", que é também o ato fundamental da experiência filosófica)" (Trigo, 2010, pp. 24-25).
} 
o viajante explorador ${ }^{2}$, o viajante conquistador ${ }^{3}$, o viajante comerciante ${ }^{4}$, o viajante pesquisador-cientista 5 , o viajante aventureiro, oflâneur e o vagabundo. Dentre eles ressaltam-se: o aventureiro, que se coloca adiante do próprio limite a desafiar o desconhecido; o flâneur e o vagabundo. Estes três tipos destacam-se na construção do viajante independente.

O flâneur, personagem francês de Walter Benjamin do fim do século XIX, expressa "o caminhar lento" que vai surgir na poesia e na filosofia (Correia, Pires \& Andrade, 2017; Figueiredo, 2010; Peixoto, 2003, p. 362). A rua é como se fosse seu lar. Percebe, por meio do olhar do "outro", a própria presença e reflexo, desejando reconhecer a alma urbana. Configura a imagem do estranho, do estrangeiro, do forasteiro, do vagabundo, aquele com potencial de ameaça. No entanto, o flâneur também decifra os códigos e signos das diversidades das coisas, pois os lugares estão carregados de almas (Yázigi, 2001) e memórias. É guiado por sua sensibilidade e interesse, isto é, por elementos subjetivos, que se estabelecem de acordo com as "funções que atribuímos ao lugar" (De Botton, 2012, p. 242).

Tuan (1980) retrata as percepções do ambiente relacionadas às manifestações de amor pelo lugar ou topofilia - em grego: Topos (lugar); Philos (amigo) - no sentido abrangente, são laços de afeição com o ambiente, elos entre a pessoa e o lugar que se difundem, por meio da experiência, que podem promover o conhecimento e expandir a identidade do sujeito com o espaço (Matos, 1997).

O viajante, retratado como o arquétipo de vagabundo, traz a "essência" do viajante sem rumo ou sem destino (Figueiredo, 2010), sem muitos objetivos, apenas pela viagem, à verdadeira guia que se desenrola em aventuras muitas vezes inusitadas e até com certos riscos:

os vagabundos aparecem ambíguos: são execrados pela sociedade capitalista, pois não dão valor algum ao trabalho, que não dignifica o homem, nem proporciona, para eles, as melhores formas de viver. Por outro lado possuem uma aura sábia valorizada em certos escritos. São Profetas, e vivem de acordo com sua própria ética. (Figueiredo, 2010, pp. 236-237)

Bauman (1998) compreende o vagabundo e o turista como figuras que se mesclam e se invejam, em que o vagabundo possui um maior desprendimento e liberdade e o turista, com seu poder de consumo, o conforto, mas que vivencia suas experiências com tempo determinado, sem muito desprendimento.

Portanto, é a partir do perfil do aventureiro, do vagabundo "sem rumo" e do flâneur, que identificamos as características e os aspectos que podem constituir no processo ou

\footnotetext{
${ }^{2} \mathrm{O}$ viajante explorador é aquele que está em busca de uma incógnita nas descobertas, equivalente à imagem de um cientista (Figueiredo, 2010).

3 O viajante conquistador traz um pouco a ideia da descoberta e o perfil do próprio explorador, mas tem caráter colonialista (Figueiredo, 2010).

${ }^{4} \mathrm{O}$ viajante comerciante para Figueiredo (2010, p. 236) é o negociador, o mercador como "arquétipo do viajante".

${ }_{5} \mathrm{O}$ viajante pesquisador-cientista acaba por conceber a viagem como uma pesquisa de campo, para estudos e desenvolvimento de métodos como a etnografia da antropologia, além dos estudos dos naturalistas (Figueiredo, 2010).
} 
na busca, a priori, por experiências significativas que vão ao encontro da imagem que compõe o viajante independente, como se ele fosse um flâneur, "reeditado" (Serrano, 2000 , p. 51), cuja presença reaviva a história do outro, ao identificar singularidades, que o outro, às vezes, já não percebe mais (Peixoto, 2003).

Em contrapartida, sua presença também pode causar inveja, por representar a liberdade, pois:

apresenta um risco moral inegável, e isso por ser portador da novidade.

$\mathrm{Na}$ verdade, essas são as próprias características da errância (...) é teste-

munha de um 'mundo paralelo', no qual o sentimento, sob suas diversas expressões, é o vagabundo, e no qual a anomia tem força de lei. (Maffesoli, 2001, p. 43)

Volta-se à nostalgia que remete a figura do viajante (Avighi, 2000) em realizar viagens que, ao mesmo tempo, propõem um desafio e remetem a aventuras, isto é, recuperam "o antigo sentimento de insegurança" que ocorreria, principalmente, no período da Idade Média (século V ao XV) e moderna (século XV ao final do XVIII) (Eco, 1984, p. 88).

Para Ortiz (2005), frente à globalização e às tecnologias, não é apenas a viagem que se banaliza, pelo fato de não apresentar mais riscos e por estar submetida a diversos interesses das instituições sociais contemporâneas. Pois, tudo, de certa forma, já é previsível, até a imaginação pelo diferente (desconhecido) é antecipada. Percebe-se também uma banalização da ação e da imagem atual do viajante, criticadas por Ortiz (2005). Pois, antigamente, suas ações eram intermediar as distâncias, incumbido de levantar informações de culturas diferentes, e a comunicação era por meio dos movimentos das viagens. Hoje, esse movimento é manipulado pelo interesse de quem elabora seu roteiro, perdendo um pouco o sentido da aventura.

Ortiz (2005) indica que o movimento, a circulação no mundo, também se domesticou. Há mais uma "familiarização" quando estamos fora do nosso país, do que certo "estranhamento", cabendo apenas à língua a existência de uma pequena tensão.

Com a quebra das fronteiras, a ideia do diferente se destitui. Ortiz (2005, p. 41) levanta a questão de como vamos viajar em um espaço tão comprimido, pois tudo caminha para nos fazer sentir "em casa". No entanto, De Botton (2012, pp. 62-63) explicita que por mais que as viagens tenham se domesticado, ainda é por meio delas que o ser humano pode encontrar a sua essência. "Não é necessariamente em casa que melhor encontramos nosso verdadeiro eu".

Por outro lado, Ortiz (2005) argumenta que a cultura popular é que vai proporcionar um mundo "diferente" para quem busca alteridade. Porém, é por meio da figura do viajante independente, o qual remete à nostalgia, que se recupera o sentido da viagem e se percebe a experiência de viajar como um "rito de passagem", fonte de transformação, formação e trocas simbólicas da vida (Pezzi \& Vianna, 2015). As trocas são compreendidas por Malinowski (1984) e Mauss (2003) como dádivas, trocas advindas do processo de ritualização no aceite ou recusa ao outro. Conjugam-se aos códigos de hospitalidades, que se estabelecem no ato de viajar. 
Figueiredo (2010) expõe a existência de três ritualizações: o contato, a troca de presente/gentilezas e familiarização. Porém, até que se tornem familiares, os "estranhos" podem ter que abrir mão de sua identidade cultural ou fazer a sua negação.

Para Ortiz (2005) a verdadeira experiência de viagem, para ser significativa, se traduz nesta forma de aproximá-la como um ritual, o qual compara com "os rituais de iniciação religiosa", como do Candomblé. Há todo um procedimento: troca do nome, corte do cabelo, isolamento por um determinado tempo, distanciamento da vida anterior. $\mathrm{O}$ autor faz uma analogia a este processo como se fosse a experiência de vivenciar em "outra" realidade, pois, quando há o retorno, "as marcas de sua iniciação a acompanharão pelo resto da vida". Percebe-se, nas viagens, elemento propiciador que separa o viajante do convívio familiar. "Depois, uma prolongada estadia on the road, para enfim reintegrá-lo em sua própria casa em sua terra de origem" (Ortiz, 2005, p. 30).

Compreende-se uma nova filosofia de viajar, de forma autônoma, influenciada por uma geração na história literária social dos anos de 1950 e 1960, denominada Beatnik (Kerouac, 2012) ${ }^{6}$. Os Beatnik são identificados como "errantes juvenis", tanto para Maffesoli (2001) como para Labate (2000). Eles rompem com a ordem das obrigações e com os obstáculos financeiros, ultrapassando as fronteiras espaciais. Na figura de viajante independente, esses errantes juvenis resumem-se ao sujeito cultural da ação, com seus poucos bens materiais em sua mochila ou mala, onde está apenas o necessário, saindo da lógica do acúmulo. A experiência de viagem, de certa forma, pode assim tornar-se mais significativa, atribuindo-se mais sentido às vivências, mediante o desprender-se, pois "quem viaja larga muita coisa na estrada. Além do que larga na partida, larga na travessia" (Ianni, 2003, p. 30), sem estar preso ao tempo social do agora.

Neste "movimento de travessia", há uma mescla ou dissolução daquilo que se tenciona ao se deparar com as "descobertas" e até com as "frustações", sendo que aquele que viaja “não é apenas um 'eu' em busca do 'outro'. Com frequência, é um 'nós' em busca dos 'outros'. O sujeito que busca sua autonomia necessita das viagens como forma de sociabilidade, de produzir cultura, de construir aprendizados, estipulando um contraponto "presente-passado-futuro" (lanni, 2003).

No mundo globalizado, populariza-se a figura do mochileiro ou backpacker, conceituado por meio de signos de independência, aventura, economia financeira e vivências culturais e pessoais, por meio das experiências significativas das viagens. $O$ viajante independente pode transfigurar ou ser identificado na personificação do mochileiro (Labate, 2000). Mas para Krippendorf (2009) há toda uma complexidade em ser um viajante, dificultando defini-lo em uma categoria. No entanto, identifica-se no quadro geral de ser viajante independente o aspecto mais característico desta experiência: a autonomia.

A partir das experiências vivenciadas de forma autônoma com o ato de viajar, se constroem também a aventura, a liberdade. Estas se conjugam aos elementos essenciais,

\footnotetext{
${ }^{6}$ Escritor canadense beatnik, Jack Kerouac (2012), escreve os manuscritos das aventuras de viagens por meio da figura literária de Sal Paradise (narrador/ personagem) em On the road de 1952. Inicia a sua viagem com apenas cinquenta dólares e sozinho, demonstrando um grande desejo em ir ao Oeste do Estados Unidos. Analisa-se Sal Paradise como aquele que escreveu suas percepções no caminho de suas viagens ao encontro dos amigos.
} 
herdados da antiga história social na formação humana no e pelo espaço por meio da errância - surgimento de um neonomadismo contemporâneo (Eco, 1984).

Ianni (2003) e Maffesoli (2001) identificam o viajante da atualidade como o novo errante, isto é, aquele com o espírito de movimento. Não são os nômades, andarilhos, migrantes, nem hippies, mas trazem as aspirações do vagabundo ou sem rumo, fazendo parte do seu imaginário a cultura de estrada que será alimentada pela aventura e pelo espírito da liberdade. Segue viagem, sem culpa social e pessoal. O novo errante associado à figura do viajante independente direciona-se, de forma consciente ou inconsciente, por uma "busca iniciática" por meio de experiências significativas, levadas a uma descoberta ou reencontro do seu "eu".

Peixoto (1987, pp. 81-82) afirma que:

a procura pela identidade tem um sentido especial (...) a história de cada um é traçada pelos lugares por onde passou. Mas essa procura (...) o leva a partir (...). O reencontro de si mesmo só pode se fazer através da viagem.

Quando se depara com a construção da personalidade do viajante (Ianni, 2003; Maffesoli, 2001), observa-se tanto a desconstrução da imagem do viajante épico, quanto a desconstrução da imagem de turista, já que ambas são estereotipadas pelo imaginário social. Porém, Cardoso (2003) adverte que não será todo ser humano disposto a se entregar à viagem desta maneira, com total independência, desapegado do conforto material, do tempo, da vida normativa e segura, deixando-se perder pelo caminho, guiado somente pelo desejo da viagem. No entanto, o ato de viajar atribui um novo sentido à existência, ao pertencimento e às formas de estar no mundo. Por meio do ato de viajar, o viajante busca o encontro da felicidade e do prazer.

Contudo, segundo Trigo (2010, p. 25), nem sempre as experiências das viagens resultam em buscas de prazer (hedônicas). Elas também podem causar sofrimento, perceptível desde o significado da palavra viagem no inglês arcaico travail, como um dos primeiros antigos conceitos, "que também significa dores do parto". Apesar de uma conotação negativa por causa do sofrimento, das experiências das viagens resultam "o autoconhecimento" e "o encontro do sentido e do significado de vida para o viajante". E podem até modificar e desconstruir a sua maneira de ver e pensar o mundo, o sentido do seu eu em sua identidade cultural, pois "aquele que parte não é nunca o mesmo que regressa" (Ianni, 2003, p. 31).

Ortiz (2005, p. 32) entende as viagens como um movimento que tem por referencial a partida e o retorno, e as compreende como um deslocamento pelo espaço descontínuo, com "cada sítio, cada cultura" constituindo "um território particular", metáfora de enriquecimento pessoal. Por outro lado, Trigo (2010) afirma que não é apenas deslocamento, mas uma jornada interior.

Segundo Figueiredo (2010, p. 247), por meio do gênero literário de relatos, a figura do viajante é estabelecida por um ser que viaja por "motivos nobres, subjetivos". O viajante independente traz a ousadia e a curiosidade como elementos que também vão levar ao encontro com o novo. E revela o desejo pela mistura, não se limitando a nenhuma 
camada social. Esta se constitui também no agrupar pela atração de estar-junto com o outro resultando também na partilha. As emoções e experiências partilhadas resultam em vetor de criação, abarcando a vida social em toda a sua conjuntura e diversidade, na composição ética da estética, por meio da errância na libertação do eu (Maffesoli, 2001).

Para Maffesoli (2001, p. 87), a existência tem um "sentido etimológico" e refere-se "a uma saída de si, uma fuga, uma explosão. Explosão que se vive no nível global, o do imaginário coletivo, mas também no próprio seio de cada indivíduo", invocando, desta forma, a partida.

A fuga é o princípio da transgressão do contrato social, ruptura com a ordem normativa "das certezas estabelecidas". Ela é crucial para romper laços maternais com o local de origem, resultando na sua negação (Mafessoli, 2001), com o intuito de se libertar das amarras institucionalizadoras típicas do pensamento moderno e da "felicidade do aprisionamento", que domesticam a aventura e a liberdade.

Verifica-se que o viajante independente tem como ponto de partida a fuga, além dos sonhos e fantasias de vivenciar experiências inusitadas. A fuga, como elemento antigo e fundamental da errância, também influencia na formação social e remete à nostalgia do viajar. Mas para que haja a fuga, é preciso suspender o dia-a-dia e ultrapassar os limites da estabilidade, se perder para depois se reencontrar (Maffesoli, 2001). Porém, não é uma suspensão definitiva (Figueiredo, 2010).

Para Cassirer (1994) por mais que o ser humano seja de fácil adaptação, há um limite para lidar com o desconhecido, que provoca o seu retorno ao local de origem. Quando o viajante independente alcança este limite, o seu retorno pode significar ter atingido o autoconhecimento, mesmo que este limite seja até mesmo físico, isto é, o limite corporal. Por outro lado, o ser humano que não ousa romper com a mesmice da vida normativa social e com laços maternais e o local de origem, pode vivenciar uma regressão de si e ter uma visão reduzida de mundo, conforme De Botton (2012).

Para o psicanalista May (2012, p. 135), a liberdade caminha ao lado da autoconsciência, pois quanto mais livres, mais obtemos autonomia e consciência, sendo "a força de amoldar e criar nós mesmos". No entanto, essa autonomia se funda na constituição da liberdade, ao assumir com responsabilidade ações e decisões próprias, o que leva a essa maior consciência de "si" e impacta como prática educativa os aprendizados por meio das vivências em sua formação e no seu processo de amadurecimento humano (Freire, 2011). Em conjunto com a coragem, estado interno que advém da conquista pela liberdade ao desafio externo, ultrapassa o "eu" moral, não colocando pudor em experimentar o novo e o acaso (May, 2012).

A liberdade também faz parte do rito de passagem (abrir-se e fechar-se), como um princípio vital. Conjuga-se a busca do longínquo, atrelada à aventura, resultando em experiências humanas (Maffesoli, 2001). A aventura pode ser definida como "um acontecimento extraterritorial" que visa uma ampla forma de se viver experiências de todas as ordens, faz parte da inquietude do viajante. Apesar de toda tecnologia, informações e simulações virtuais, ela só se permite em "tempo real", em experiências culturais, sendo testemunha de enriquecimento cultural concebido por meio das fantasias e mobilidade 
(Ortiz, 2005, p. 46). Quando abertos para o mundo, resulta em novas ressignificações identitárias.

O viajante independente pode demonstrar aspectos dúbios em relação à errância, pois assume papéis de múltiplas identidades. Acerca disso, May (2012, p. 46) afirma que as múltiplas identidades são exercidas pelos nossos selves (identidade pessoal), mas não é uma simples somatória de nossas representações, e sim a conscientização de diferentes facetas de nossas personalidades exercidas, que podem evoluir, mas não é um processo simples e repentino. Elas estabelecem um princípio de pares de opostos tanto para Durkheim e Mauss (1984), Maffesoli (2001), como também para Lévi-Strauss (2009), ao salientarem a formação da estrutura social e pessoal, por exemplo, ao implicar num conectar-desconectar e enraizar-errar. É por meio do errar, desviar e da partida que as polaridades das diferenças são evidenciadas e interiorizadas, proporcionando sentido ao ser (Hall, 2005). O território integra-se e interage com o imaginário, com o mundo simbólico da existência.

Por sua vez, a errância também propicia "enraizamento-dinâmico", pois ao mesmo tempo em que expressa uma "passagem", o acaso pode também ser intencional e enraizar o que se mostra pontual aos interesses do viajante. Este sabe o valor da necessidade da distância, do desfazer dos vínculos e do desapegar. Contudo, ao mesmo tempo em que o viajante se afasta, leva uma parte consigo nas lembranças e nas habilidades desenvolvidas perante as situações ocasionais e aprendizagens com o outro. No entanto, o sentir livre reflete-se na felicidade, no conhecimento e acaba por se predispor à "aventura e ao encontro" (Maffesoli, 2001).

A felicidade se mostra paradoxal (Lipovetsky, 2007). Revela um homo viator dos novos tempos "de aspirações desmesuradas e de desejos sempre insatisfeitos", encontrada no mundo dos efêmeros, sendo este um dos aspectos das patologias sociais da hipermodernidade (Maffesoli, 2001, p. 87). No entanto, atenta-se que o efêmero não só faz parte do cotidiano sufocante, mas faz parte do próprio ser, mediante o conhecimento assimilado do contato cultural, da linguagem com o outro. Nesse sentido, o viajante apresenta uma vida com identidades contraditórias, constitui uma figura frágil, pois é uma identidade que se constrói e descontrói em movimento.

Hall (2005) explicita que tanto no pensamento pós-moderno, quanto no decorrer da globalização ocidental, o sujeito não terá uma identidade permanente. No processo de construção da identidade cultural, o deslocamento é parte da externalização que completa esta construção, "impactada pela compressão espaço-tempo". Pode-se fortalecer ou produzir novas identidades nas esferas locais ou globais, conjugadas ao advento do turismo (das viagens turísticas) que se torna um dos responsáveis pela pluralização cultural ou por reinventar ou preservar culturas tradicionais e agente da construção social na formação da identidade. Contudo, nesse cenário dos efeitos da globalização, contraditórios e conexos, ocorre uma crise e fragmentação das identidades proporcionadas por uma crescente homogeneização e heterogeneidade da cultura e estabelecidas por identidades híbridas ${ }^{7}$ pelas comunidades imaginadas. Essas comunidades são

7 O fenômeno de hibridação, teorizado pelo pensador contemporâneo argentino Canclini (2008), é um processo sociocultural que estabelece o sentido de mesclas interculturais e desvincula-a da noção de puro e autêntico, relacionando o 
construídas mentalmente por meio dos sistemas de representação cultural dominante, sustentadas também pelos ritos, códigos sociais e costumes cotidianos (Hall, 2005). Há um jogo de negociações na produção das identidades, que impacta no ser humano.

Woodward (2007) acentua que nas identidades seu conjunto é conflituoso, mas também pode coexistir uma coerência. A luta por sua autenticidade é apenas um modo de se legitimar, porém está sempre associada à construção cultural e histórica, à memória, aos interesses ideológicos. E, obviamente, devido a uma situação de alteridade, está associada também às relações interpessoais, que podem dar novos sentidos à existência do ser e podem provocar sentimentos de pertencimento social ao se identificar com o outro. Para a autora, as identidades são construções simbólicas influenciadas pela cultura.

Nesse viés, Ortiz (2005) compreende que as identidades são virtuais, ou seja, não apresentam uma existência real, apenas quando possui referenciais simbólicos na relação com a cultura, o gênero, a etnia, a nação. No entanto, a identidade é uma construção histórica e não biológica (Hall, 2005). É cambiável no tempo, porém, é vista como forma de legitimar a existência, sustentada pela memória com as lembranças na releitura do passado. Candau (2012) afirma, com base nos estudos das teorias de memória, que é a partir das lembranças que a memória se compõe, constituindo e (re)formulando e (re) significando a nossa identidade marcada pelas experiências e aprendizagens mais profundas que compreendem o ser em sua totalidade, ou seja, conforme as suas tríplices dimensões - corporais, sociais e psicológicas - atribuídas por Mauss (2003).

Dessa forma, necessita-se do nômade, do estranho e do estrangeiro que configuram o viajante, para renovar a cultura, produzir e provocar as diferenças. Sua presença pode impactar na cultura, e em identidades, somente quando houver trocas (relações afetivas e sociais) (Matos, 1997). A identidade cultural do sujeito depende das experiências vivenciadas e dos "múltiplos elementos presentes na memória cultural do indivíduo" e é assumida em diversos papéis sociais manifestados em avaliações de conceitos e valores de mundo.

Nesse viés, Figueiredo (2010) expressa o quanto são ricos os relatos de viagens, pois elas se configuram mais significativas quando registradas por meio da experiência pessoal. Observa-se o enriquecimento pessoal (reformulação, adaptação e reconstrução de valores humanos) e social, isto é, como o ser humano que viaja se vê pós a viagem e como reflete ou percebe "os outros". Os relatos deixam perceptíveis a transformação, a construção e o desenvolvimento da figura do viajante independente, pautando-se em características fundamentais: na errância, na liberdade e na aventura. Estas características conjugadas no interior daquele que viaja se transformam em experiências significativas. Para fazer uma aproximação com esta assertiva, observa-se brevemente os relatos reais de Chris McCandless (Krakauer, 1998) e Antonio Lino (Lino, 2011).

fenômeno com as práticas ou estruturas que se separam, combinam-se e podem formar novas estruturas, práticas, produções de criação culturais ao coletivo ou ao indivíduo ocasionados pelos movimentos migratórios, turísticos, intercâmbios das comunicações etc., consequentes do advento da tecnologia e desterritorialização. O autor visa tratar do conceito de cultura numa abordagem intercultural. 


\section{VIAJANTES INDEPENDENTES: RELATOS LITERÁRIOS DE EXPERIÊNCIAS SIGNIFICATIVAS DE VIAGENS}

No caso de Chris McCandless, seus escritos e as memórias de seus feitos foram reconstituídos e organizados por meio de conclusões hipotéticas com base em reuniões de cartas, fotografias e depoimentos, e na própria história de vida quando jovem, pelo jornalista e escritor americano Jon Krakauer no livro Na natureza selvagem [Into the wild]. O jornalista ficou muito tocado com a história após o editor da revista Outside lhe pedir para realizar uma reportagem acerca da morte de McCandless em uma jornada ao Alasca. Após o livro, foi feita a produção cinematográfica, dirigida por Sean Penn em 2007, com o mesmo título.

Christopher Johnson McCandless, de 24 anos, era jovem da classe média alta da costa leste dos Estados Unidos. Larga a faculdade (idealizada pelos pais), doando todo o dinheiro destinado a seu estudo a uma instituição de caridade (Krakauer, 1998). Esta passagem reflete todo o conflito pessoal, político e ideológico vivido pelo jovem em plena década de 1990.

A obsessão com a viagem seria também uma realização de um sonho de infância, alimentado cada vez mais com suas leituras: ir ao norte, "viver da terra". Chris McCandless "buscava a pulsão vital da existência" (Krakauer, 1998, p. 34). Cultivava o desejo de estar só em plena região "selvagem" no Alasca. Ele mesmo se referia a esta experiência como "a grande odisseia". Desliga-se da família, para a qual nunca mandou notícias por dois anos de (1990 a 1992), pois tinha muito ressentimento. Nega a sua identidade. Inicia o seu destino a pé, após o desastre com o carro no deserto. Queima seu dinheiro como uma forma de negar toda a vida burguesa, pois alegava que não precisava de muito, somente o que poderia carregar e levar em sua mochila de essencial. "Saindo de Atlanta para o oeste (...) Para simbolizar o corte completo com sua vida anterior (...). Não mais atenderia por Chris McCandless; era Alexandre Supertramp, senhor de seu próprio destino" (Krakauer, 1998, p. 34).

Vive grandes aventuras, encontra pessoas que o afetaram e foram afetadas por ele, apesar de sempre procurar a distância. O Alasca era uma forma de estar apenas consigo mesmo e com a natureza. O jovem procurava evitar cargas emocionais. Krakauer (1998) define que Chris não era um vagueante ou alienado: sua caminhada era filosófica.

Segue ao caminho do Norte, do Alasca, para sua aventura definitiva em Strampede Trail, uma trilha da década de 1930 feita para abrir caminho a um projeto de mineração, situada no monte Mckinley, no Parque Nacional Denali. Nas proximidades havia um ônibus que ficou abandonado após o fracasso do projeto que serviu a ele como abrigo e lar (Krakauer, 1998, p. 172). E foi neste ônibus que encontram o corpo de Chris. Deixou escrito em seu diário que estava assustado, pois teria tentado cruzar o rio Teklanika; "Mccandless aprendeu um dos axiomas fundamentais (embora paradoxal) do Norte: a melhor estação para viajar por terra não é o verão, é o inverno" (Krakauer, 1998, p. 173); mas como se encontrava muito debilitado e com quase nenhum equipamento adequado, seria impossível.

Krakauer (1998) interpreta o escrito de Chris Alexandre Supertramp como alguém "eufórico" e independente quando instalado no interior do Alasca: 
um viajante estético cujo lar é a estrada. (...) A batalha final para matar o ser falso interior e concluir vitoriosamente a revolução espiritual. Dez dias e noites de trens de carga e pegando carona (...). Para não mais ser envenenado pela civilização, ele foge e caminha sozinho sobre a terra para perder-se na natureza (Alexandre Supertramp, Maio de 1992). (Krakauer, 1998, p. 172)

O Alasca é visto como a sua grande auto-realização e renascimento. A natureza selvagem é a nossa própria natureza, "nossa busca, nosso encontro". No entanto, as experiências trágicas e estes momentos de contato com a natureza, com o singelo da vida, nos transportam a sublimação das coisas e das emoções e, neste processo, constituem os laços e o conhecimento. O Alasca despertou as perturbações de Chris, como em todo lugar quando se está em silêncio e solitário, revelados no desejo por voltar para o convívio em sociedade, em suas escritas por socorro. Principalmente, no escrito que Chris conclui ao relatar que a verdadeira felicidade era aquela que se compartilha com outro, encontrada na obra Doutor Jivago de Boris Pasternak, demonstrando sabedoria e autoconhecimento adquiridos pela viagem, uma experiência significativa para sua existência. O isolamento no Alasca fez Chris perceber que, além da natureza, o afeto humano também é importante. Verifica-se também nas escritas de socorro que Chris, ao assina-las, não mais se identifica por Alexandre Supertramp, identidade constituída no desenvolvimento da sua experiência, e sim pelo seu nome verdadeiro Christopher Johnson McCandless: "abandonou o apelido pretensioso que vinha usando havia anos, Alexandre Supertramp, em favor do nome que recebeu de seus pais ao nascer" (Krakauer, 1998, p. 205).

Evidenciando-se que apesar da experiência sofrida em alguns momentos pelo isolamento consequentes do inverno e falta de alimento, também foi vital para possível compreensão de sua própria natureza, de si próprio, levando-o assinar com seu próprio nome; após muito tempo vivendo de sementes, acaba morrendo de inanição. Alguns acreditam que ele tenha confundido uma planta do Alasca comestível por outra venenosa que, por seu corpo já estar debilitado, intoxicou-o ao ponto de levá-lo à morte.

A errância de Chris resultou em demonstração de afeto, solidariedade e generosidade. "Ele não era simplesmente um andarilho comum (...) McCandless deixou uma impressão indelével em várias pessoas, a maioria das quais passou somente poucos dias em sua companhia, no máximo uma semana ou duas" (Krakauer, 1998, p. 59). Chris era um viajante, independente, solitário, sonhador, cuja formação e identidade foram se desenvolvendo e tomando outros sentidos, construídos e descontruídos pela/na experiência, a qual tinha como busca sua essência, o significado de vida na esfera espiritual, principalmente. E talvez, se tivesse vivido, em vez de ser uma conclusão tomada por hipóteses, reunião de cartas e depoimentos organizados por um jornalista, saberíamos por ele mesmo o dia-a-dia no Alasca e com a publicação de seu próprio diário como aconteceu com Antonio Lino.

O relato de Antonio Lino, intitulado o Encaramujado: uma viagem de Kombi pelo Brasil - e pelos Cafundós de mim, foi publicado em 2011. Lino (2011) tem a profissão de 
escritor. Figueiredo (2010) frisa a necessidade de atenção crítica aos escritos de viagem. Há invariavelmente uma tentativa de mostrar ao leitor determinada representação da realidade vivida pelo autor. Lino (2011) revela que no momento anterior à viagem estava precisando de inspirações e reflexão para o caminhar de sua vida. Além disso, possuía uma grande ambição de conhecer o próprio país, sua cultura e natureza, ao materializar-se, alegando a idealização pela vivência da experiência, após ler $A$ arte de viajar ${ }^{8}$ de Alain de Botton, reafirma o desejo pela viagem. Apesar de não nos interessar os meios, e sim a experiência, ela se tornou mais significativa por ser realizada numa Kombi.

Lino deixa claro no seu relato o anseio por uma experiência fora do comum, mas que é influenciado pela leitura da obra Os argonautas da cosmopolita de um escritor argentino, Julio Cortázar, o qual realiza uma viagem pela França com sua esposa, de Kombi. Foi por meio dessa leitura, confessa Lino (2011, p. 24) que se deu o ponto de partida: "pegando carona na história alheia, decidi (...) minha viagem também seria numa Kombi", sendo uma forma de economizar tanto na hospedagem como em meios de transporte, o que traz a alusão do "caramujo". Metaforiza o único lar que podemos carregar, nossa essência e nossos "eus", deixando claro logo de início, em seu relato, que os seus objetivos principais, além da ambição de conhecer o Brasil, sua cultura e natureza, estão em se conhecer, buscar a si mesmo. Resolve, assim, descobrir sua essência na estrada, pois para Lino (2011, p. 11) "viajar é sair para dentro".

Para De Botton (2012) e lanni (2003) a viagem possui uma estreita metáfora com a imaginação. A imaginação do viajante está presente desde o momento que antecede a sua partida e também é produzida pelos ouvintes ou leitores ao embarcar nos relatos das experiências de viagens alheias. Fernando Pessoa (1986), poeta e escritor, com o semi-heterônimo de Bernardo Soares na Obra Livro do Desassossego, adverte que o viajante não precisa necessariamente se deslocar para viajar. Para o poeta, a imaginação e a criatividade definem o maior viajante.

A viagem para Lino só se conclui um ano após sua idealização. Revela-se complicado este começo do desapego da segurança do dia-a-dia de São Paulo. Lino se caracteriza no começo do relato como o "carcereiro" que prende seu "eu", mas que precisa sentir, refletir, se libertar... ser anônimo. Larga o emprego, faz algumas economias. Além da compra da Kombi, não leva nada mais do que a si mesmo: "ao se livrar dos excedentes, (...), o viajante se amplia ao essencial” (Lino, 2011, p. 10).

Lino (2011, p. 11) entrega-se ao desconhecido e aos acasos da experiência, aos 27 anos de idade "sem lugar certo para ir, nem hora marcada para voltar", durante um ano e três meses de viagem. Depara-se com paisagens que o elevam a uma reflexão sobre a vida. Ao retornar a São Paulo, afirma no relato que a experiência de viagem acarreta um reencontro de um eu barbudo com outras convicções de vida que se integra ao outro eu (carcereiro) que havia deixado para trás: "tanto quanto a ida, a volta também é a jornada (...) colocarei à prova minha capacidade de encontrar poesia no cotidiano. (...) aprendi

\footnotetext{
${ }^{8} \mathrm{Na}$ obra A arte de viajar De Botton (2012), em viagem a Amsterdão, associa suas reflexões ao lugar, através dos seus guias de influência literária, filosófica e artística originários dos países visitados, como Flaubert, que já dizia que o local que provocasse nossa atração e amor era aquele em que estava a nossa identidade, este seria o verdadeiro local de origem.
} 
com os caramujos: eu sou a minha casa (...) paredes não aprisionam espíritos livres" (Lino, 2011 p. 252).

Peixoto (1987) afirma que quando o viajante se deixa envolver, sem pressa, no processo da experiência de viagem, pode chegar ao ponto de perceber o mundo como sua morada.

De Botton (2012) explica que a volta para casa, depois de uma profunda experiência de viagem, pode-se revelar perturbadora para o espírito humano, como se verifica na percepção do viajante Lino ao reencontro do "eu barbudo" com o "eu carcereiro". Porém, ao mesmo tempo, o retorno atribui novos sentidos e poesia à cidade natal que não eram mais percebidos na rotina do cotidiano. De Botton (2012) chega à conclusão que o verdadeiro prazer da viagem não depende somente do lugar, mas do nosso estado de espírito.

A experiência de viagem que se interpreta em relatos dos viajantes independentes Antonio Lino e Chris McCandless, ou entre outros viajantes ficcionais ou reais, demostra que as viagens são verdadeiras "parteiras de pensamentos" afim de conduzir-nos na conversa com os próprios monstros e conflitos, na leitura sobre si mesmo, aliada a liberdade, errância e a aventura, acarretando no desenvolvimento da autonomia de si ao fazer as próprias escolhas (De Botton, 2012, p. 60). O processo da experiência de viagem acaba por se constituir numa experiência educativa, que transforma e forma o ser humano.

Por fim, as viagens são vistas como práticas transformadoras do sentido da vida, sendo também aspiradas como uma arte da expressão humana, consequentes dessas experiências significativas, podendo refletir na auto-realização, na reformulação da identidade cultural e numa construção social e pessoal do viajante independente.

\section{CONSIDERAÇÕES FINAIS}

A viagem, assim como a vida, é a verdadeira "arte do encontro" dos versos de Vinicius de Morais". As viagens são como nossa paixão, pela qual nos perdemos e também nos buscamos. $\mathrm{O}$ ato de perder-se nas viagens pode gerar educação que se configura com as experiências significativas fazendo parte da nossa história e memória atreladas ao outro. "A viagem é memória do percurso (...) Viajar é o encontro do viajante consigo mesmo (...) não é apenas deslocar-se" (Matos, 1997, pp. 134-135).

As experiências de viagens se revelam significativas, pois fazem o ser humano viver a liberdade, coletar valores sentimentais, potencializar a imaginação, as inquietudes ou até as frustrações daquele que se desloca. Podem até modificar a significação do tempo e espaço, atribuir ao ser humano novas formas para desenhar o mundo: são verdadeiras marcas na essência humana. Elas se revelam como uma busca por outras "qualidades de que carecemos". Quando vinculado a um lugar ou alguém, podem estreitar-se os "valores que faltam em nossa cultura" e identidades (De Botton, 2012, p. 90).

May (2012) ressalta que apenas em momentos raros, em atos singulares, quando se vivencia algo especial, é que se instauram a autoconsciência e a práxis criativa, o

\footnotetext{
${ }_{9}^{9}$ Música: Samba da Bênção - Vinicius de Moraes e Baden Powell, década de 1960.
} 
sentido de si e da ação para o sujeito, que vai influir na identidade, isto é, na formação de nós mesmos, pois a autoconsciência implica no autoconhecimento, na autoafirmação de si. Ocasiona-se, geralmente, quando se afasta do tempo da rotina, como nas viagens e quando se predispõe a se abrir ao outro diferente de si.

A experiência de viagem independente é análoga ao rito de passagem ou ao um movimento de travessia na vivência para outra realidade, proporcionando o (re)encontro com o seu "outro", irreconhecível para si próprio. Assim, demonstra-se como um momento sagrado e ao mesmo tempo profano (lanni, 2003), advindos da liberdade, da aventura e da errância. $O$ ato independente de viajar afirma-se como uma experiência significativa, pois se configura como "o modo de descobrir o 'outro', além de um modo de descobrir o 'eu'" (Figueiredo, 2010, p. 251).

Contudo, a experiência de viagem pode revelar momentos e épocas inesquecíveis para a vida. Quando desacompanhados e independentes, os viajantes estão livres para expressar suas estranhezas e decisões. "Toda viagem se destina a ultrapassar fronteiras, tanto dissolvendo-as como recriando-as. (...) Projeta no espaço e no tempo um eu nômade, reconhecendo as diversidades (...) ao mesmo tempo recriam identidades, proliferam diversidades" (lanni, 2003, pp. 13-14). As experiências significativas de viagens formam, desconstroem, modificam e constroem este eu que se desloca com autonomia, o viajante independente, pois à medida que mergulha em si mesmo, se solta, se liberta, se lança "pelo caminho e pela imaginação", os hábitos mudam e se desenvolvem habilidades: o "caminho se faz".

\section{REFERÊNCIAS}

Araújo, E., Cogo, D. \& Pinto, M. (2015). Mobilidades, media(ções), culturas. Comunicação e Sociedade, 28, 7-14. DOI: $10.17231 /$ comsoc.28(2015).2267

Avighi, C. M. (2000). Turismo, globalização e cultura. In B. H. G. Lages \& P. C. Milone (Eds.), Turismo: teoria e prática (pp. 102-106). São Paulo: Altas.

Bauman, Z. (1998). O mal-estar da pós-modernidade. Rio de Janeiro: Jorge Zahar.

Canclini, N. G. (2008). Culturas híbridas: estratégias para entrar e sair da modernidade. São Paulo: USP.

Candau, J. (2012). Memórias e identidades. São Paulo: Contexto.

Cardoso, S. (2003). O olhar dos viajantes [do etnólogo]. In A. Novais (Ed.), O olhar (pp. 347-36o). São Paulo: Companhia das Letras.

Cassirer, E. (1994). Ensaio sobre o homem: introdução a uma filosofia da cultura humana. São Paulo: Martins Fontes.

Correia, M. da L., Pires, H. \& Andrade, P. (2017). Passeio, passante, passeante. Uma plataforma de arte e cultura urbana. Revista Lusófona de Estudos Culturais, 3(2), 167- 183. Retirado de http://www.rlec.pt/ index.php/rlec/article/view/184/147

De Botton, A. (2012). A arte de viajar. Rio de Janeiro: Intrínseca.

Durkheim, E. \& Mauss, M. (1984). Algumas formas primitivas de classificação. In J. A. Rodrigues \& E. Durkheim (Eds.), Sociologia (pp. 183-203). São Paulo: Ática. 
Eco, U. (1984). Viagem na irrealidade cotidiana. Rio de Janeiro: Nova Fronteira.

Figueiredo, S. L. (2010). Viagens e viajantes. São Paulo: Annablume.

Freire, P. (2011). Pedagogia da autonomia: saberes necessários à prática educativa. São Paulo: Paz e Terra.

Giddens, A. (2003). Mundo em descontrole: o que a globalização está fazendo de nós. Rio de Janeiro: Record.

Gil, A. C. (2002). Como elaborar projeto de pesquisa. São Paulo: Atlas.

Hall, S. (2005). A identidade cultural na pós-modernidade. Rio de Janeiro: DP\&A.

Ianni, O. (2003). Enigmas da modernidade-mundo. Rio de Janeiro: Civilização Brasileira.

Kerouac, J. (2012). On the road: o manuscrito original. Porto Alegre, RS: L\&PM.

Krakauer, J. (1998) Na natureza selvagem. São Paulo: Companhia das Letras.

Krippendorf, J. (2009). Sociologia do turismo: para uma nova compreensão do lazer e das viagens. São Paulo: Aleph.

Labate, B. C. (2000). A experiência do "viajante-turista" na contemporaneidade. In C. Serrano; H. T. Bruhns \& M. T. D. P. Luchiari (Eds.), Olhares contemporâneos sobre o turismo (pp. 55-80). Campinas: São Paulo: Papirus.

Lévi-Strauss, C. (2009). As estruturas elementares do parentesco. Petrópolis: Vozes.

Lino, A. (2011). Encaramujado: uma viagem de Kombi pelo Brasil (e pelos cafundós de mim). São Paulo: Antonio Lino.

Lipovetsky, G. (2004). Os tempos hipermodernos. São Paulo: Editora Barcarolla.

Lipovetsky, G. (2007). A felicidade paradoxal: ensaio sobre a sociedade do hiperconsumo. São Paulo: Companhia das letras.

Maffesoli, M. (2001). Sobre o nomadismo: vagabundagens pós-modernas. Rio de Janeiro: Record.

Magris, C. (2008). El infinito. Barcelona: Anagrama.

Malinowsk, B. K. (1984). Argonautas do Pacífico Ocidental: um relato do empreendimento e da aventura dos nativos nos arquipélagos da Nova Guiné Melanésia. São Paulo: Abril Cultural.

Martins, G. de A. \& Theóphilo, C. R. (2007). Metodologia da investigação científica para ciências sociais aplicadas. São Paulo: Atlas.

Matos, O. C. F. (1997). História viajante: notações filosóficas. São Paulo: Studio Nobel.

Mauss, M. (2003). Sociologia e antropologia. São Paulo: Cosac \& Naify.

May, R. (2012). O homem à procura de si mesmo. Rio de Janeiro: Voz.

Ortiz, R. (2005) Um outro território: ensaios sobre a mundialização. São Paulo: Olho D’Água.

Panosso Netto, A. (2010). Experiência e turismo: uma união possível. In A. Panosso Netto \& C. Gaeta (Eds.), Turismo de experiência (pp. 43-55). São Paulo: SENAC.

Peixoto, N. B. (1987). Cenários em ruínas: a realidade imaginária contemporânea. Editora: Brasiliense. 
Peixoto, N. B. (2003). O olhar do estrangeiro. In A. Novaes (Ed.), O olhar (pp. 361-365). São Paulo: Companhia das Letras.

Pessoa, F. (1986). Livro do desassossego. Por Bernardo Soares. São Paulo: Editora Brasiliense.

Pezzi, E. \& Vianna, S. L. G. (2015). A experiência turística e o turismo de experiência: um estudo sobre as dimensões da experiência memorável. Revista Turismo em Análise, 26(1), 165-187.

Salazar, N. B. (2017). Key figures of mobility: an introduction. Social Anthropology, 25(1), 5-12.

Salgueiro, V. (2002). Grand Tour: uma contribuição à história do viajar por prazer e por amor à cultura, Revista Brasileira de História, 22(44), 289-310. DOI: /10.1590/S0102-01882002000200003

Serrano, C. (2000). Poéticas e políticas das viagens. In C. Serrano; H.T. Bruhns \& M. T. D. P. Luchiari (Eds.), Olhares contemporâneos sobre o turismo (pp. 37-53). Campinas: São Paulo: Papirus.

Trigo, L. G. G. (1998). A sociedade pós-industrial e o profissional em turismo. Campinas, São Paulo: Papiros.

Trigo, L. G. G. (2010). A viagem como experiência significativa. In A. Panosso Netto \& C. Gaeta (Eds.), Turismo de experiência (pp. 21-41). São Paulo: SENAC.

Tuan, Y. F. (1980). Topofilia: estudo da percepção, atitudes e valores do meio ambiente. São Paulo: DIFEL.

Urry, J. (1996). O olhar do turista: lazer e viagens nas sociedades contemporâneas. São Paulo: Studio Nobel: SESC.

Woodward, K. (2007). Identidade e diferença: uma introdução teórica e conceitual. In T. T. Silva; S. Hall \& K. Woodward (Eds.), Identidade e diferença: a perspectiva dos Estudos Culturais (pp. 7 -72). Petrópolis- RJ: Vozes.

Yázigi, E. (2001). Alma do lugar: turismo, planejamento e cotidiano em litoral e montanha. São Paulo: Contexto.

\section{NotAs BiográficAs}

Camila Aparecida Leves Maneze, Graduada em Lazer e Turismo pela Escola de Artes, Ciências e Humanidades da Universidade de São Paulo. Mestranda em Turismo pelo Centro de Excelência em Turismo da Universidade de Brasília, Brasil.

Email: hp_ca22@hotmail.com

Morada: Rua Dom Meinrado, 110, O2961/140 - São Paulo - Brasil

Reinaldo Tadeu Boscolo Pacheco, Doutor em Educação pela Universidade de São Paulo. Professor no curso de graduação em Lazer e Turismo e no mestrado em Ciências da Atividade Física na Escola de Artes, Ciências e Humanidades da Universidade de São Paulo, Brasil.

Email: repacheco@usp.br

Endereço: Rua Arlindo Bettio, 1000, 03828-000, Campus Universitário Leste - São Paulo- Brasil

\footnotetext{
* Submetido: $28-02-2018$

* Aceite: 30-06-2018
} 